\title{
Cryogenic Aerosol Generation: Airborne Mist Particles Surrounding Liquid Nitrogen
}

\author{
Byung Uk Lee
}

Aerosol and Bioengineering Laboratory, College of Engineering, Konkuk University, 120 Neungdong-ro, Gwangjin-gu, Seoul 05029, Korea; leebu@konkuk.ac.kr

Received: 30 December 2019; Accepted: 5 February 2020; Published: 7 February 2020

\begin{abstract}
Aerosol mist particles generated near the surface of a liquid nitrogen container were measured and analyzed. The particles present at various distances from the boiling surface of liquid nitrogen were detected using an optical particle counter. In this experiment, 3 micrometer particles exhibited a more than 100-fold increase in concentration due to the liquid nitrogen surface. However, 0.3 micrometer and 10 micrometer particles showed smaller variations ( $2 \%$ to $79 \%$ ) in their concentrations in the vicinity of liquid nitrogen. The distance from the boiling surface of the liquid nitrogen strongly affected the variations in particle concentration. The variations in aerosol concentrations were significant within $20 \mathrm{~cm}$ of the liquid nitrogen surface. These results can be considered as a useful quantitative environmental guideline in cryogenic studies that use liquid nitrogen, and this concept can be applied to cryogenic aerosol mist generation mechanisms.
\end{abstract}

Keywords: liquid nitrogen; cryogenics; aerosol generation; low temperature energy; air quality

\section{Introduction}

Aerosol generation mechanisms have been researched and used in various aerosol studies [1-4]. Liquid nebulizers, air feeders, and spark generators have been developed for submicron particles, coarse particles, and nanoparticles, respectively, for aerosol experimental purposes [5-7]. Pressurized liquid sprays and electrosprays have also been used to generate fine mist particles [8,9]. Mixing gases and combustion have been considered as secondary particle generation methods for a gas to particle conversion mechanism and an incomplete oxidation byproduct particle production, respectively [10]. In this study, a novel concept of environmental aerosol generation is introduced and tested.

Liquid nitrogen (LN2) is widely used for the refrigeration of various engineering systems (for example, a magnetic resonance imaging (MRI) device) and the preservation of biological materials [11]. It is also used for studies on superfluids (liquid helium) and superconductors. At a pressure of 1 atmosphere $(1 \mathrm{~atm}=1.104 \mathrm{bar})$, liquid nitrogen starts boiling at $77 \mathrm{~K}\left(-196.15^{\circ} \mathrm{C}\right)$ and generates cold conditions in the air of the surrounding environment. In previous aerosol studies, liquid nitrogen has been used to maintain temperature gradient conditions in a low temperature range for thermophoresis [12].

In this study, aerosol particle fumes generated in the vicinity of liquid nitrogen were investigated using aerosol experimental methods. The particle fumes from the liquid nitrogen were analyzed in terms of their aerosol particle sizes and concentrations with temperature and humidity values. In this experiment, the distance of sampling locations from the boiling surface of liquid nitrogen was considered a parameter that affects the fumes from the liquid nitrogen. The diameters of the measured aerosol mist particles ranged from 0.3 to $10 \mu \mathrm{m}$. These particles were estimated to be affected by the condensation near the surface of liquid nitrogen. The size distributions and concentrations of aerosol particles were analyzed in terms of the ratio of the various mist-generated concentrations to the ordinary aerosol concentration. The experimental results showed that the concentrations of aerosol 
mist particles were strongly affected by the liquid nitrogen up to a distance of $20 \mathrm{~cm}$ from the liquid nitrogen surface, whereas they returned to their ordinary levels at distances greater than $30 \mathrm{~cm}$ from the liquid nitrogen surface. These experiments demonstrate that liquid nitrogen environments can be regarded as a method of mist particle generation for energy and environmental studies. In addition, the generated particles in the vicinity of a liquid nitrogen container can be used for studying air quality control devices for public health issues.

\section{Methods}

Figure 1 shows the schematic diagram of the experimental setup. The chamber containing liquid nitrogen was designed and fabricated. Inside the chamber $(20 \times 12 \times 5 \mathrm{~cm}), 1.2$ liters of liquid nitrogen were located and boiled at $77 \mathrm{~K}$. The aerosol particles were sampled at distances of 10, 20, 30, 40, and $50 \mathrm{~cm}$, and $1 \mathrm{~m}$ above the liquid nitrogen surface. The particle sizes and concentrations were measured using an optical particle counter (OPC; Portable particle counter, Model 3910, KANOMAX, Andover Township, NJ, USA). In the OPC, aerosol particles passed through a device in which the scattering signals between sampled particles and laser radiation light were translated into data for aerosol sizes and concentrations. The sampling flow rate was $28.3 \mathrm{~L} / \mathrm{min}$ and the sampling time was 30 s per sample. The optical particle counter had six channels of sizes: $0.3 \mu \mathrm{m}(0.3 \leq \mathrm{D}<0.5 \mu \mathrm{m})$, $0.5 \mu \mathrm{m}(0.5 \leq \mathrm{D}<1 \mu \mathrm{m}), 1 \mu \mathrm{m}(1 \leq \mathrm{D}<3 \mu \mathrm{m}), 3 \mu \mathrm{m}(3 \leq \mathrm{D}<5 \mu \mathrm{m}), 5 \mu \mathrm{m}(5 \leq \mathrm{D}<10 \mu \mathrm{m})$, and 10 $\mu \mathrm{m}(10 \mu \mathrm{m} \leq \mathrm{D})$. In addition, the temperature and relative humidity values were measured at the individual locations using a hygrometer (Testo 625, Germany). The laboratory environment where the experiment took place was air-conditioned, controlled (closed), and $6.9 \mathrm{~m}$ wide, $10.1 \mathrm{~m}$ long, and 2.7 $\mathrm{m}$ high. This environment was large enough to not be completely influenced by the liquid nitrogen. During the analysis, experimental results were converted into the ratio of aerosol mist concentrations to the ordinary (without $\mathrm{LN}_{2}$ ) indoor aerosol concentrations of the experimental environments, which is a particle concentration ratio, as expressed below:

$$
\text { Particleconcentration ratio }=\frac{\text { Particleconcentration with } L_{2}}{\text { Particleconcentration without } \mathrm{LN}_{2}}
$$

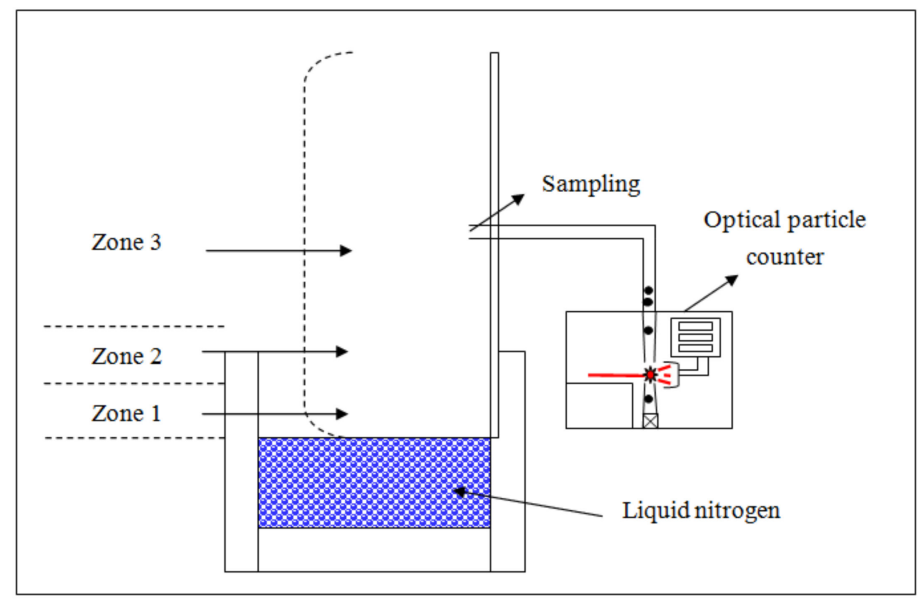

Figure 1. Schematic diagram of the experimental setup.

For each individual condition, experiments were repeated at least three times in this study. 


\section{Results and Discussion}

Table 1 lists the temperature and relative humidity values of the experimental locations. It can be observed that the temperature and humidity values show slight variations $\left(\Delta \mathrm{T}: 0.6^{\circ} \mathrm{C} ; \Delta \mathrm{RH}: 5.4 \%\right)$ in the vicinity of $\mathrm{LN}_{2}$.

Table 1. Temperature and relative humidity values in the vicinity of liquid nitrogen $\left(\mathrm{LN}_{2}\right)$.

\begin{tabular}{ccc}
\hline & Temperature $\left({ }^{\circ} \mathrm{C}\right)$ & Relative Humidity (\%) \\
\hline Without $\mathrm{LN}_{2}$ & $25.2 \pm 0$ & $64.9 \pm 0.1$ \\
\hline $10 \mathrm{~cm}$ from $\mathrm{LN}_{2}$ & $25.8 \pm 0.1$ & $62.1 \pm 0.2$ \\
\hline $20 \mathrm{~cm}$ from $\mathrm{LN}_{2}$ & $25.8 \pm 0.1$ & $63.8 \pm 0.1$ \\
\hline $30 \mathrm{~cm}$ from $\mathrm{LN}_{2}$ & $25.5 \pm 0$ & $64.6 \pm 0.1$ \\
\hline $40 \mathrm{~cm}$ from $\mathrm{LN}_{2}$ & $25.3 \pm 0$ & $67.5 \pm 0.1$ \\
\hline $50 \mathrm{~cm}$ from $\mathrm{LN}_{2}$ & $25.3 \pm 0$ & $66.8 \pm 0.1$ \\
\hline $100 \mathrm{~cm}$ from $\mathrm{LN}_{2}$ & $25.2 \pm 0$ & $64.9 \pm 0.1$ \\
\hline
\end{tabular}

Figure 2 shows the concentrations of aerosol particles in the ordinary air environments of the experimental room without $\mathrm{LN}_{2}$. The concentrations of aerosol particles ranged from $10^{7}$ to $10^{4}$ particles $/ \mathrm{m}^{3}$ for the particles, with sizes ranging from 0.3 to $10 \mu \mathrm{m}$. The replicative measurements showed that the fluctuation (standard deviations) in the particle concentrations was less than $58 \%$ of the average concentration.

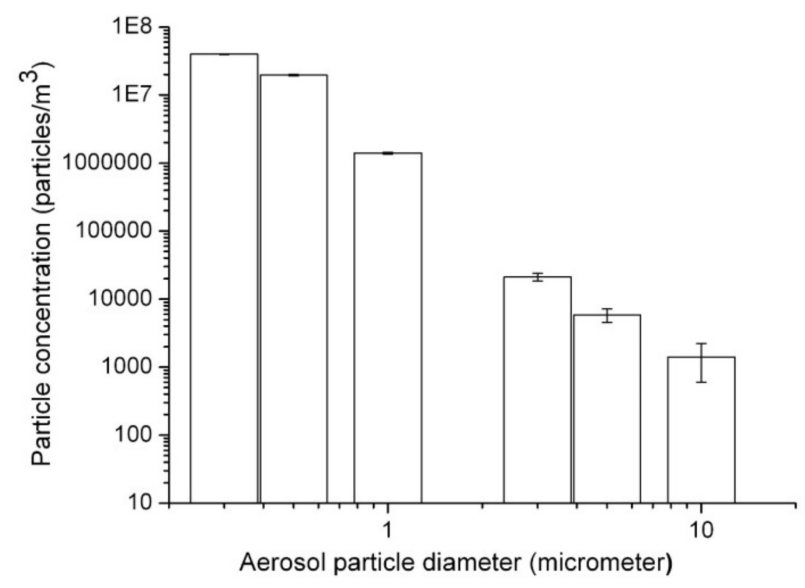

Figure 2. Aerosol particle size distributions in the experimental air environments (without $\mathrm{LN}_{2}$ ).

Table 2 presents the concentrations and optical sizes of aerosol particles with variations in distances from the $\mathrm{LN}_{2}$ boiling surface. Figure 3 shows the particle concentration ratios (the ratios of particle concentrations in the vicinity of liquid nitrogen to the ordinary particle concentrations) of $3 \mu \mathrm{m}$ particles with respect to the distance from the $\mathrm{LN}_{2}$ surface. For the $3 \mu \mathrm{m}$ particles, the concentration $10 \mathrm{~cm}$ above the $\mathrm{LN}_{2}$ surface increased from $2.1 \times 10^{4}$ particles $/ \mathrm{m}^{3}$ without $\mathrm{LN}_{2}($ ratio $=1)$ to $3.68 \times 10^{6}$ particles $/ \mathrm{m}^{3}$ $($ ratio $=173)$, indicating an increase of $>100$ times with statistical significance $(t$-test $p$-value $<0.05)$. At distances of $20 \mathrm{~cm}$ and $30 \mathrm{~cm}$ from the $\mathrm{LN}_{2}$ surface, the concentrations were $3.20 \times 10^{5}$ particles $/ \mathrm{m}^{3}$ $($ ratio $=15)(t$-test $p$-value $<0.05)$ and $1.89 \times 10^{4}$ particles $/ \mathrm{m}^{3}$ (ratio $\left.=0.89\right)(t$-test $p$-value $>0.05)$, respectively. At distances greater than $30 \mathrm{~cm}$ from the $\mathrm{LN}_{2}$ surface, the concentration of these particles became similar ( $45 \%$ to $89 \%$ ) to the ordinary indoor aerosol concentration without $\mathrm{LN}_{2}$. 
Table 2. Aerosol particle concentrations (particles $\left./ \mathrm{m}^{3}\right)$ in the vicinity of liquid nitrogen $\left(\mathrm{LN}_{2}\right)$.

\begin{tabular}{|c|c|c|c|c|c|c|}
\hline & $0.3 \mu \mathrm{m}$ & $0.5 \mu \mathrm{m}$ & $1 \mu \mathrm{m}$ & $3 \mu \mathrm{m}$ & $5 \mu \mathrm{m}$ & $10 \mu \mathrm{m}$ \\
\hline Without $\mathrm{LN}_{2}$ & $4.0 \times 10^{7} \pm 3.0 \times 10^{5}$ & $2.0 \times 10^{7} \pm 4.0 \times 10^{5}$ & $1.4 \times 10^{6} \pm 4.4 \times 10^{4}$ & $2.1 \times 10^{4} \pm 2.9 \times 10^{3}$ & $5.9 \times 10^{3} \pm 1.3 \times 10^{3}$ & $1.4 \times 10^{3} \pm 8.1 \times 10^{2}$ \\
\hline $10 \mathrm{~cm}$ from $\mathrm{LN}_{2}$ & $8.4 \times 10^{6} \pm 3.6 \times 10^{6}$ & $8.4 \times 10^{6} \pm 1.1 \times 10^{6}$ & $3.2 \times 10^{7} \pm 7.0 \times 10^{6}$ & $3.7 \times 10^{6} \pm 5.3 \times 10^{5}$ & $1.6 \times 10^{5} \pm 3.1 \times 10^{4}$ & $3.3 \times 10^{2} \pm 8.1 \times 10^{1}$ \\
\hline $20 \mathrm{~cm}$ from $\mathrm{LN}_{2}$ & $3.9 \times 10^{7} \pm 6.4 \times 10^{5}$ & $1.8 \times 10^{7} \pm 8.2 \times 10^{5}$ & $2.0 \times 10^{6} \pm 1.3 \times 10^{5}$ & $3.2 \times 10^{5} \pm 1.4 \times 10^{5}$ & $7.3 \times 10^{4} \pm 6.7 \times 10^{4}$ & $8.2 \times 10^{2} \pm 5.1 \times 10^{2}$ \\
\hline $30 \mathrm{~cm}$ from $\mathrm{LN}_{2}$ & $4.1 \times 10^{7} \pm 2.6 \times 10^{5}$ & $1.8 \times 10^{7} \pm 6.5 \times 10^{5}$ & $1.2 \times 10^{6} \pm 2.6 \times 10^{4}$ & $1.9 \times 10^{4} \pm 2.8 \times 10^{3}$ & $3.9 \times 10^{3} \pm 1.1 \times 10^{3}$ & $6.8 \times 10^{2} \pm 2.9 \times 10^{2}$ \\
\hline $40 \mathrm{~cm}$ from $\mathrm{LN}_{2}$ & $4.2 \times 10^{7} \pm 3.3 \times 10^{5}$ & $1.6 \times 10^{7} \pm 7.4 \times 10^{5}$ & $1.1 \times 10^{6} \pm 6.9 \times 10^{4}$ & $1.5 \times 10^{4} \pm 2.6 \times 10^{3}$ & $3.5 \times 10^{3} \pm 1.8 \times 10^{3}$ & $1.4 \times 10^{3} \pm 1.0 \times 10^{3}$ \\
\hline $50 \mathrm{~cm}$ from $\mathrm{LN}_{2}$ & $4.2 \times 10^{7} \pm 6.0 \times 10^{4}$ & $1.4 \times 10^{7} \pm 3.3 \times 10^{5}$ & $9.4 \times 10^{5} \pm 2.1 \times 10^{4}$ & $1.1 \times 10^{4} \pm 9.3 \times 10^{2}$ & $3.4 \times 10^{3} \pm 1.5 \times 10^{3}$ & $1.1 \times 10^{3} \pm 3.2 \times 10^{2}$ \\
\hline $100 \mathrm{~cm}$ from $\mathrm{LN}_{2}$ & $4.2 \times 10^{7} \pm 1.1 \times 10^{5}$ & $1.2 \times 10^{7} \pm 2.3 \times 10^{5}$ & $8.1 \times 10^{5} \pm 2.9 \times 10^{4}$ & $9.6 \times 10^{3} \pm 6.0 \times 10^{2}$ & $2.9 \times 10^{3} \pm 9.4 \times 10^{2}$ & $5.9 \times 10^{2} \pm 1.1 \times 10^{2}$ \\
\hline
\end{tabular}




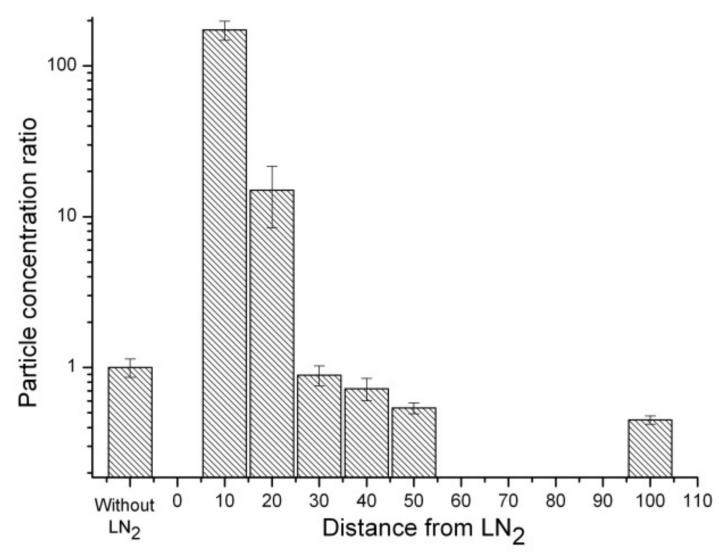

Figure 3. Concentration ratios of particles of size $3 \mu \mathrm{m}$ at distances of 10, 20, 30, 40, 50, and $100 \mathrm{~cm}$ from the $\mathrm{LN}_{2}$ surface.

Figures 4 and 5 show the concentration ratios for particles of sizes 5 and $1 \mu \mathrm{m}$, respectively, showing the distances from the $\mathrm{LN}_{2}$ surface. The concentrations of $5 \mu \mathrm{m}$ particles were $1.63 \times 10^{5}$ particles $/ \mathrm{m}^{3}($ ratio $=27.6)(t$-test $p$-value $<0.05), 7.30 \times 10^{4}$ particles $/ \mathrm{m}^{3}($ ratio $=12.4)(t$-test $p$-value $>0.05)$, and $3.86 \times 10^{3}$ particles $/ \mathrm{m}^{3}$ (ratio $\left.=0.66\right)(t$-test $p$-value $>0.05)$ at distances of $10 \mathrm{~cm}, 20 \mathrm{~cm}$, and $30 \mathrm{~cm}$ above $\mathrm{LN}_{2}$ surface, respectively. The concentrations of particle size $1 \mu \mathrm{m}$ were $3.15 \times 10^{7}$ particles $/ \mathrm{m}^{3}($ ratio $=22.5)(t$-test $p$-value $<0.05), 2.00 \times 10^{6}$ particles $/ \mathrm{m}^{3}($ ratio $=1.4)(t$-test $p$-value $<$ 0.05 ), and $1.25 \times 10^{6}$ particles $/ \mathrm{m}^{3}$ (ratio $\left.=0.89\right)(t$-test $p$-value $<0.05$ ) at distances of $10 \mathrm{~cm}, 20 \mathrm{~cm}$, and 30 $\mathrm{cm}$ above the $\mathrm{LN}_{2}$ surface, respectively. These particles $(3 \mu \mathrm{m}, 5 \mu \mathrm{m}, 1 \mu \mathrm{m})$ showed an extreme increase in their concentrations from 173 times (particles of size $3 \mu \mathrm{m}$ ) to 22.5 times (particles of size $1 \mu \mathrm{m}$ ) more particles than the ordinary indoor conditions without $\mathrm{LN}_{2}$ boiling at $10 \mathrm{~cm}$ above the $\mathrm{LN}_{2}$ surface.

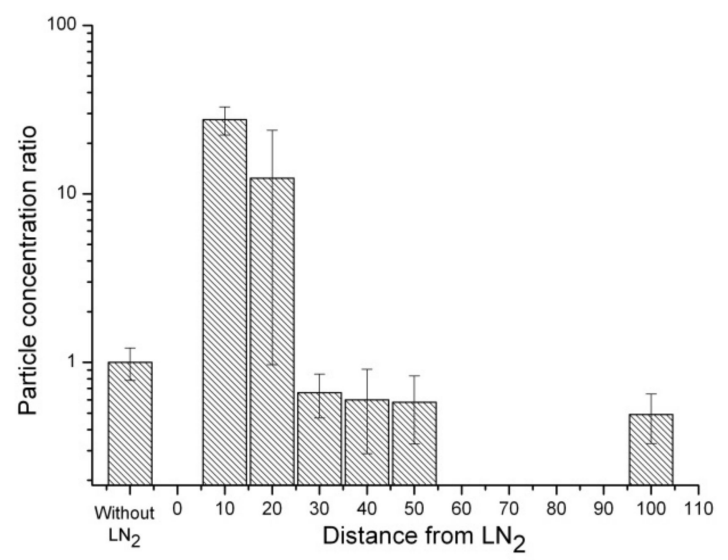

Figure 4. Concentration ratios of particles of size $5 \mu \mathrm{m}$ at distances of 10, 20, 30, 40, 50, and $100 \mathrm{~cm}$ from the $\mathrm{LN}_{2}$ surfaces. 


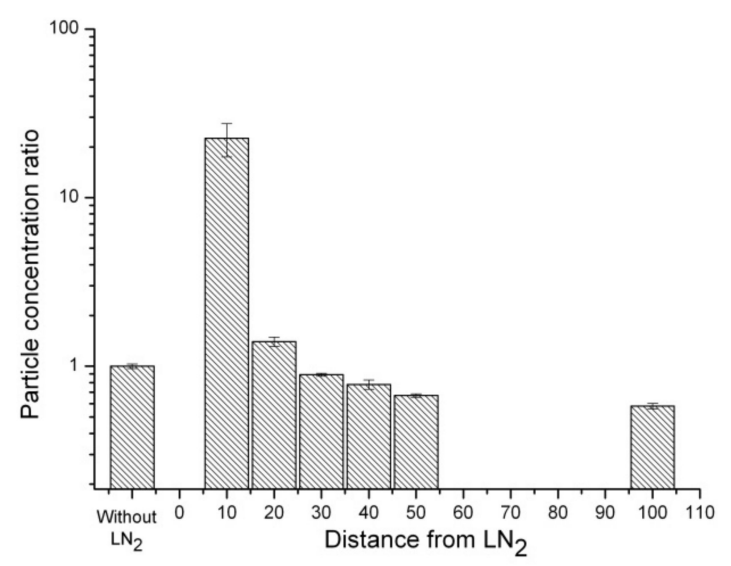

Figure 5. Concentration ratios of particles of size $1 \mu \mathrm{m}$ at distances of 10, 20, 30, 40, 50, and $100 \mathrm{~cm}$ from the $\mathrm{LN}_{2}$ surfaces.

However, the submicrometer-sized particles of 0.3 and $0.5 \mu \mathrm{m}$ showed different trends, as shown in Table 2. At $10 \mathrm{~cm}$ above the $\mathrm{LN}_{2}$ surface, the concentrations of submicrometer-sized particles became $21 \%$ ( $79 \%$ decrease) ( $t$-test $p$-value $<0.05)$ and $43 \%$ (57\% decrease) $(t$-test $p$-value $<0.05)$, respectively, of their ordinary indoor concentrations with statistical significance. The concentrations of these particles decreased, whereas the concentrations of particles of sizes 1,3, and $5 \mu \mathrm{m}$ increased in the vicinity of $10 \mathrm{~cm}$ of the $\mathrm{LN}_{2}$ boiling surface. The decrease in the concentrations of submicrometer-sized particles became insignificant at a distance of more than $20 \mathrm{~cm}$ above the $\mathrm{LN}_{2}$ surface; for example, the concentrations of 0.3 and $0.5 \mu \mathrm{m}$ particles recovered by $98 \%$ ( $t$-test $p$-value $>0.05)$ and $94 \%$ ( $t$-test $p$-value $<0.05$ ) of their ordinary indoor concentrations at the distance of $20 \mathrm{~cm}$, respectively.

Throughout the experiment, variations in the concentrations of particles decreased as the distance from the $\mathrm{LN}_{2}$ surface increased. At the distances of $30 \mathrm{~cm}, 40 \mathrm{~cm}, 50 \mathrm{~cm}$, and $1 \mathrm{~m}$ from the $\mathrm{LN}_{2}$ surface, the concentrations of $3 \mu \mathrm{m}$ particles, which were highly affected by $\mathrm{LN}_{2}$, showed similar concentration levels to the surrounding ordinary aerosol concentrations ( $45 \%$ to $89 \%$ of the ordinary concentrations). Above $30 \mathrm{~cm}$ from the $\mathrm{LN}_{2}$ surface, other aerosol particles showed similar concentrations ( $42 \%$ to $103 \%$ of ordinary concentrations) to the fluctuated indoor particle concentrations without $\mathrm{LN}_{2}$.

These experimental results can be explained by dividing the nearby space of $\mathrm{LN}_{2}$ in the following way. The zones of the $\mathrm{LN}_{2}$ were divided into three groups: within $10 \mathrm{~cm}$ (zone 1), 10 to $20 \mathrm{~cm}$ (zone 2), and more than $30 \mathrm{~cm}$ (zone 3) environments from the $\mathrm{LN}_{2}$ boiling surface, as shown in Figure 1. Figure 6 shows a model of transition of the aerosol particles in the zones.

In the zone 1 environment ( $10 \mathrm{~cm}$ from the $\mathrm{LN}_{2}$ surface), the variation in the particle concentrations can be explained by the fact that submicron particles present on the surface transformed into particles of sizes ranging from 1 to $5 \mu \mathrm{m}$ due to the condensation of surrounding gases on the submicron particles. Then, the grown aerosol particles floated and spread near the $\mathrm{LN}_{2}$ surface environments (Figure 6). As shown in Table 1, the decreased concentrations of particles of sizes 0.3 and $0.5 \mu \mathrm{m}$ are $-3.2 \times 10^{7}$ and $-1.1 \times 10^{7}$ particles $/ \mathrm{m}^{3}$, respectively. The increased concentrations of particles of sizes 1,3 , and 5 $\mu \mathrm{m}$ are $3.0 \times 10^{7}, 3.7 \times 10^{6}$, and $1.6 \times 10^{5}$ particles $/ \mathrm{m}^{3}$. This result can be interpreted as particles of sizes 0.3 and $0.5 \mu \mathrm{m}\left(4.3 \times 10^{7}\right.$ particles $\left./ \mathrm{m}^{3}\right)$ transform into particles of sizes 1,3 , and $5 \mu \mathrm{m}\left(3.4 \times 10^{7}\right.$ particles $/ \mathrm{m}^{3}$ ) because of the condensation and possible merging of particles caused by $\mathrm{LN}_{2}$ (Figure 6). 


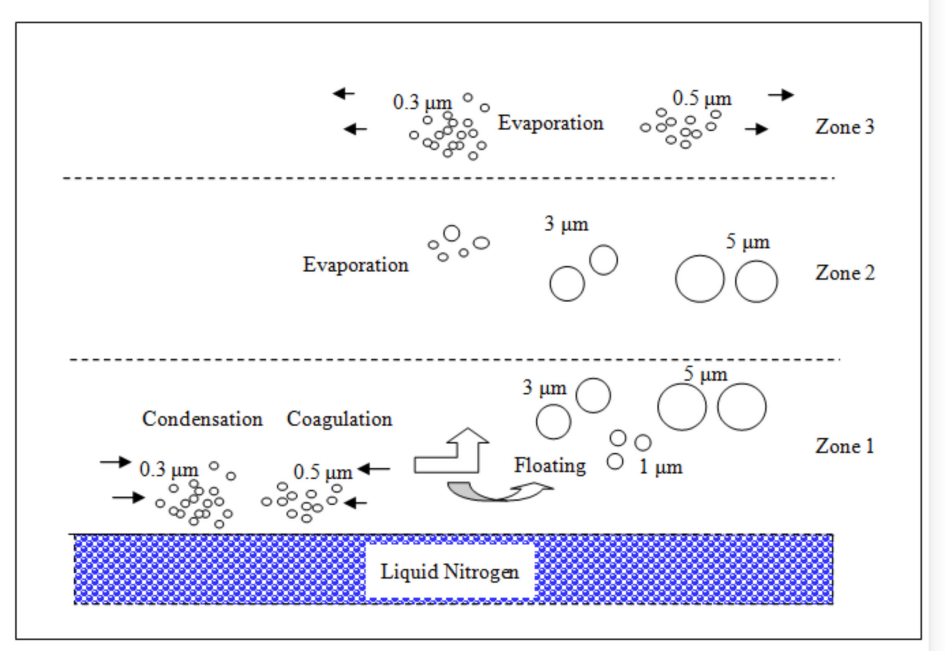

Figure 6. Model of transition of aerosol particles in the vicinity of the $\mathrm{LN}_{2}$ surfaces.

In zone 2 (10 $\mathrm{cm}$ to $20 \mathrm{~cm}$ from the $\mathrm{LN}_{2}$ surface), the floated particles of sizes ranging from 3 to 5 $\mu \mathrm{m}$ maintained their shapes. However, particles of other sizes, such as $1 \mu \mathrm{m}$ and submicrometer-sized particles, returned to their original shape. This resulted in decreased aerosol concentrations of the 1 $\mu \mathrm{m}$ particles present at this location. This change was estimated to be a result of the evaporation of condensed materials present on the surfaces of $1 \mu \mathrm{m}$ particles (Figure 6).

In the zone 3 environment ( $30 \mathrm{~cm}$ from the $\mathrm{LN}_{2}$ surface), the concentration of aerosol particles approached the ordinary fluctuating concentrations of the surrounding experimental environments without $\mathrm{LN}_{2}$. The floating mist particles could not be influenced over $30 \mathrm{~cm}$ from the $\mathrm{LN}_{2}$ surface under this experimental condition.

The general equation for the concentration of the aerosol particles could be expressed by the following differential form:

$$
\frac{\partial n_{k}}{\partial t}+\nabla \cdot n_{k} \vec{V}=\left(\nabla \cdot D \nabla n_{k}\right)_{\text {diffusion }}+\left[\frac{\partial n_{k}}{\partial t}\right]_{\text {growth }}-\left[\frac{\partial n_{k}}{\partial t}\right]_{\text {evaporation }}+\left[\frac{\partial n_{k}}{\partial t}\right]_{\text {coagulation }}
$$

Equation (2) is a differential equation of specific-sized particle concentrations, " $n_{k}$ ". For 0.3 and $0.5 \mu \mathrm{m}$ particles, condensational growth $\left[\frac{\partial n_{k}}{\partial t}\right]_{\text {growth }}$ and coagulations $\left[\frac{\partial n_{k}}{\partial t}\right]_{\text {coagulation }}$ transformed them (decease of concentration) into 1, 3, and $5 \mu \mathrm{m}$ particles (increase of concentration) in zone 1 of Figure 6. However, $1 \mu \mathrm{m}$ particles experienced evaporation $-\left[\frac{\partial n_{k}}{\partial t}\right]_{\text {evaporation }}$ in zone 2 . Therefore, the concentrations of $0.3 \mu \mathrm{m}$ particles and $0.5 \mu \mathrm{m}$ particles increased, while that of $1 \mu \mathrm{m}$ particles decreased in zone 2. The condensation, coagulation, and evaporation occurred in zones 1 and 2 . However, the floating aerosol mist particles from the $\mathrm{LN}_{2}$ surface could not approach the distant zone 3 .

For the generation of aerosol particles, it can be considered that more than ten times the number of particles with diameters ranging from 1 to $5 \mu \mathrm{m}$ can be artificially generated using the $\mathrm{LN}_{2}$ surface, and this can be treated as a cryogenic aerosol generator for these particles. For the generation of 3 and $5 \mu \mathrm{m}$ mist particles, we can use the environments 10 and $20 \mathrm{~cm}$ (zone 1 and zone 2) from the $\mathrm{LN}_{2}$ surface. For the generation of $1 \mu \mathrm{m}$ aerosol mist particles, we can use the environment $10 \mathrm{~cm}$ (zone 1) from the $\mathrm{LN}_{2}$ surface. Therefore, the environments of the $\mathrm{LN}_{2}$ surface can be used for the momentary generation of aerosol mist particles, of sizes ranging from 1 to $5 \mu \mathrm{m}$.

These experimental results can have several potential applications. First, it can be recognized that aerosol mist particles of sizes 1,3 , and $5 \mu \mathrm{m}$ are generated in surrounding environments when $\mathrm{LN}_{2}$ is used in working places, such as the preservation process for biological materials and the cooling process for superconducting devices. Any particle-sensitive device can be affected in a precautionary working 
place with $\mathrm{LN}_{2}$. Second, the generated particles from $\mathrm{LN}_{2}$ can be used for testing control devices targeting smog mist particles. There are demands for the development of control devices against smog aerosol mist particles which are hazardous to human health $[13,14]$. The mist particles generated from $\mathrm{LN}_{2}$ can be used as test aerosols for a high-concentration test of the control devices with easy treatments after experiments due to its short residence time. Further new applications can be developed using this newly found cryogenic aerosol generation mechanism. There are limitations to this study. Experiments with various environmental conditions, such as very dry or humid situations, can be conducted with more controlled fluctuations in aerosol particle concentrations in the experimental chamber. Measurements via other devices, such as an aerodynamic particle spectrometer, which has more size channels, and other nanoparticle detection devices, can be considered in future studies.

\section{Conclusions}

In this study, aerosol mist particles of sizes ranging from 1 to $5 \mu \mathrm{m}$ were generated in the vicinity of 10 to $20 \mathrm{~cm}$ from the $\mathrm{LN}_{2}$ boiling surface. In particular, the $3 \mu \mathrm{m}$ particles were strongly affected by the $\mathrm{LN}_{2}$ environments. These experimental results are estimated due to the condensation, evaporation, and floating of particles in the vicinity of the $\mathrm{LN}_{2}$ surface. Different zones of the $\mathrm{LN}_{2}$ surface can be used as cryogenic aerosol generating spaces for aerosol studies. However, there are limitations to this study. For example, the number of division of sampling distances from the $\mathrm{LN}_{2}$ boiling surface to the outside could be considered. In addition, further studies need to be conducted for a lifetime study of the generated mist particles. This experimental result can provide useful information on the applications of liquid nitrogen.

Funding: This research received no external funding.

Conflicts of Interest: The author declares no conflicts of interest.

\section{References}

1. Eisner, A.D.; Martonen, T.B. Properties of satellite and primary aerosols from a modified may spinning-top aerosol generator. J. Aerosol Sci. 1988, 19, 307-315. [CrossRef]

2. Fu, H.; Patel, A.C.; Holtzman, M.J;; Chen, D.R. A New Electrospray Aerosol Generator with High Particle Transmission Efficiency. Aerosol Sci. Technol. 2011, 45, 1176-1183. [CrossRef] [PubMed]

3. Kang, Y.C.; Park, S.B. A high-volume spray aerosol generator producing small droplets for low pressure applications. J. Aerosol Sci. 1995, 26, 1131-1138. [CrossRef]

4. Ulevicius, V.; Willeke, K.; Grinshpun, S.A.; Donnelly, J.; Lin, X.; Mainelis, G. Aerosolization of Particles from a Bubbling Liquid: Characteristics and Generator Development. Aerosol Sci. Technol. 2007, 26, 175-190. [CrossRef]

5. Ahmad, S.; Laiho, P.; Zhang, Q.; Jiang, H.; Hussain, A.; Liao, Y.; Ding, E.X.; Wei, N.; Kauppinen, E.I. Gas phase synthesis of metallic and bimetallic catalyst nanoparticles by rod-to-tube type spark discharge generator. $J$. Aerosol Sci. 2018, 123, 208-218. [CrossRef]

6. $\quad$ Longest, P.W.; Spence, B.M.; Holbrook, L.T.; Mossi, K.M.; Son, Y.J.; Hindle, M. Production of inhalable submicrometer aerosols from concentional mesh nebulizers for improved respiratory drug delivery. J. Aerosol Sci. 2012, 51, 66-80. [CrossRef] [PubMed]

7. Reist, P.C.; Taylor, L. Development and operation of an improved turntable dust feeder. Powder Technol. 2000, 107, 36-42. [CrossRef]

8. Kim, K.; Kim, W.; Yun, S.H.; Lee, J.H.; Kim, S.S.; Lee, B.U. Use of an electrospray for the generation of bacterial bioaerosols. J. Aerosol Sci. 2008, 39, 365-372. [CrossRef]

9. Jeong, S.B.; Chong, E.S.; Heo, K.J.; Lee, G.W.; Kim, H.J.; Lee, B.U. Electrospray patterning of yeast cells for applications in alcoholic fermentation. Sci. Rep. 2019, 9, 18662. [CrossRef] [PubMed]

10. Friedlander, S.K. Smoke, Dust, and Haze: Fundamentals of Aerosol Dynamics; Oxford University Press: New York, NY, USA, 2000.

11. Barron, R.F. Cryogenic Systems, 2nd ed.; Oxford University Press: New York, NY, USA, 1985. 
12. Lee, B.U.; Kim, S.S. Thermophoresis in the cryogenic temperature range. J. Aerosol Sci. 2001, 32, 107-119. [CrossRef]

13. Hu, H.; Pan, J. The risk assessement of the fog disaster. J. Risk Anal. Crisis Response 2011, 1, 59-64. [CrossRef]

14. Cai, D.P.; He, Y.M. Daily lifestyles in the fog and haze weather. J. Thorac. Dis. 2016, 8, E75-E77. [PubMed]

(C) 2020 by the author. Licensee MDPI, Basel, Switzerland. This article is an open access article distributed under the terms and conditions of the Creative Commons Attribution (CC BY) license (http://creativecommons.org/licenses/by/4.0/). 